\title{
RESPONSE OF LEMNA MINOR CLONES TO MICROCYSTIS TOXICITY
}

\author{
KovÁts, $\mathrm{N}{ }^{*}-$ Ács, A. ${ }^{1}-$ PAUlovits, $\mathrm{G}^{2}{ }^{2}-$ VASAS, ${ }^{3}{ }^{3}$ \\ ${ }^{1}$ University of Pannonia, Department of Limnology, \\ 8200 Veszprém, P.O.Box 158, Hungary \\ (phone: +36-88-624496) \\ e-mail:kovats@almos.vein.hu \\ ${ }^{2}$ Balaton Limnological Institute of the Hungarian Academy of Sciences, \\ 8235 Tihany, P.O.Box 35, Hungary \\ e-mail:paulo@tres.blki.hu \\ ${ }^{3}$ University of Debrecen, Department of Botany, \\ 4032 Debrecen, P.O.Box 14, Hungary \\ e-mail:vasasg@tigris.unideb.hu \\ (Received $15^{\text {th }}$ September 2010 ; accepted $14^{\text {th }}$ February 2011)
}

\begin{abstract}
Tests based on the growth inhibition of Lemna minor are widely used in ecotoxicology. The assessment endpoint is the development of new fronds, which is not only a rapid response but is also of ecological significance. At present this is the only standard ecotoxicological test in Europe which uses a higher aquatic plant species, so toxic effect of different contaminants should be extrapolated to other macrophytes. As it might be suspected that cyanobacteria and macrophytes are in a competitive interaction, more and more studies are targeted to reveal the mechanisms via cyanobacterial toxins explicate inhibitory effect. In order to find out what actual risk cyanobacterial toxicity might pose on coexisting Lemna populations, Lemna growth inhibition tests were carried out using duckweed clones collected from different natural habitats. Striking differences were found, identifying clones showing normal reproduction in the presence of Microcystis aeruginosa but on the contrary, other clones showed not only reproduction inhibition but visual symptoms such as chlorosis and necrosis.
\end{abstract}

Keywords: Lemna minor, ecological risk assessment, ToxAlert, microcystin

\section{Introduction}

The Lemna minor growth inhibition test is widely used in ecotoxicology, several standard test protocols are available. In addition to national protocols, international standards also apply: OECD Guidelines for the Testing of Chemicals: Lemna sp. Growth Inhibition Test, Draft Guideline 221 (OECD 2002) and the ISO/FDIS 20079 standard which has been recently introduced in Hungary (ISO/FDIS 20079: Water quality - Determination of the toxic effect of water constituents and waste water on duckweed (Lemna minor) - Duckweed growth inhibition test). The aim of using a standard protocol is to quantify the ecological effect of a given toxicant (in this case cyanobacterial toxins), to make results comparable and if required, to extrapolate the results to other taxa. At present this test is the only bioassay in Europe which uses a higher plant species and should be able to provide reliable data for assessing risk posed on macrophytes. Microcystis - Lemna interaction is of significance because real-world interaction (competition) might be suspected. As such, the main target of this study was to reveal the uncertainty factors the standard Lemna test might have. Our null hypothesis was that in eutrophic habitats where toxic blooms occur, naturally coexisting Lemna populations might develop some resistance against cyanobacterial 
toxins and will show reduced sensitivity in comparison to previously non-exposed cultures.

\section{Review of literature}

Of cyanobacterial toxins, the hepatotoxin microcystin produced by Microcystis, Planktothrix (Oscillatoria) and Anabaena sp. is probably posing the highest environmental risk. Up to now over 60 variants of this toxin have been identified, of them microcystin-LR seems to be the most widespread (e.g. Sivonen and Jones, 1999). These variants differ in their toxic potential, microcystin-LR being one of the most toxic, with an $\mathrm{LD}_{50} \mu \mathrm{g} / \mathrm{kg}$ bw (based on the mouse assay). The WHO Guideline prescribes an $1 \mu \mathrm{g} / 1$ limit value for this variant in treated drinking water.

However, different other toxic compounds have been isolated from Microcystis such as cyanopeptolins (e.g. von Elert et al., 2005), or micropeptins (e.g. Ishida et al., 1997). Jungmann (1995) reported that aqueous extacts of Microcystis that were free of microcystins were proven toxic in bioassays.

It is a rather general phenomenon that microcystins do have inhibitory effects on growth of different duckweed species. Jang et al. (2007) gave evidence about reciprocal allelopathic responses between Microcystis aeruginosa and Lemna japonica. Various ecological symptoms have been investigated, such as biochemical responses (e.g. Yi et al., 2009), reduction of chlorophyll-a content and photosynthetic capacity (e.g. Weiss et al., 2000) and growth impairment. Romanowska-Duda and Tarczynska (2002) used Spirodela oligorrhiza and found that in the presence of 0.2 and $0.1 \mu \mathrm{g} / \mathrm{l}$ of MC-LR the reduction in the number of fronds was apparent after 24 hours of exposure. In a study conducted by Mitrovic et al. (2005), not only symptoms such as reduction in weight and frond number were recorded but bioaccumulation was also observed. Although most studies have been concentrating on planktonic strains, Mohamed and Al Shehri (2010) demonstrated that toxin production in epiphytic cyanobacteria can also affect aquatic plants.

Studies conducted on other aquatic plants have also shown clear response to Microcystis toxicity (e.g. Pflugmacher et al., 2001a; Pflugmacher, 2004; Yin et al., 2005). Pflugmacher (2002) tested microcystin-LR for its allelopathic power on aquatic macrophytes such as Ceratophyllum demersum and Myriophyllum spicatum, and found that exposure results in growth inhibition, reduction in photosynthetic oxygen production, and changes in pigment pattern. Szigeti et al. (2010) reported growth inhibition in Ceratophyllum demersum via MCY-LR-induced inhibition of cell elongation. It has been shown that microcystins inhibit photosynthetic activity in various plants (e.g. Pflugmacher et al., 2001b; Wiegand et al., 2002). Máthé et al. (2007). established the histological effects of exposure to microcystin-LR (MC-LR), a cyanotoxin on axenic Phragmites australis plantlets, describing e.g. aerenchyma obturation, the premature development of lateral roots, even root necrosis. Leaf necrosis was also reported (Babica et al., 2006). In addition to microcystins, several other metabolites produced by Microcystis were shown to have inhibitory effect on photoautrophs (e.g. Wiegand et al., 2002).

Some of the mechanisms via plants might develop resistance to cyanobacterial toxicity have been documented. It has been demonstrated that some species of green algae e.g. Scenedesmus sp. coexist and even flourish in the presence of either toxic cyanobacteria or their toxins (Sedmak and Kosi, 1998). Mohamed (2008) investigated 
the possible adaptive response of two representatives of green algae, Chlorella vulgaris and Scenedesmus quadricauda to pure microcystin-LR (MCYST-LR) and crude MCYSTs. During the first 3 days of exposure, both pure and crude MCYSTs significantly decreased the growth of the two algae compared to control cultures. Meanwhile, increases in glutathione-S-transferase (GST), glutathione peroxidase (GPX) and lipid peroxidation were also observed in toxin-treated cultures, finally growth and biochemical variables were restored and remained at levels near to those of control cultures. These results may suggest that polysaccharides might function as a protective agent in some microalgae against MCYST- induced oxidative stress. Stüven and Pflugmacher (2007) tested the effect of cyanobacterial toxins as well as cyanobacterial crude extract containing microcystins-LR and provided evidence of oxidative stress response in Lepidium sativum seedlings, manifested by lipid peroxidation, elevation of alpha- and beta-tocopherol concentrations and elevated activities of antioxidative enzymes like the glutathione peroxidase, glutathione S-transferase and glutathione reductase. Kamara and Pflugmacher (2007) suggested that in aquatic macrophytes increase in antioxidative enzyme levels can be part of the protection strategy of against oxidative stress.

\section{Materials and methods}

\section{Sample collection}

Ecotoxicity testing was carried out using liophilised Microcystis aeruginosa samples which were collected in the Kis-Balaton Water Protection System.

For preparing test samples, first a $2 \mathrm{mg}$ liophilised Microcystis $/ \mathrm{ml}$ test solution was prepared, than a 1:2:4:8:16 dilution series was set.

\section{Lemna minor growth inhibition test}

\section{Lemna clones}

5 duckweed clones were used for comparison, collected from natural wetlands and semi-natural ponds as follows: Lemnal from a slow-flowing stream, Lemna2 from an oligotrophic pond, Lemna3 and 4 from a slightly eutrophic pond and its tributary, and finally, Lemna5 test population was collected from the Kis-Balaton Water Protection System (a restored wetland in fact), where co-existence with Microcystis is proven.

\section{Experimental procedure}

The tests were carried out in accordance with the OECD Guideline 221 (Lemna sp. Growth Inhibition Test). Duckweeds consisting of 2 fronds were selected and 10-10 colonies were transferred to each test vessel, thus the starting frond number was 20 . Frond numbers and the appearance of the colonies were recorded on Day4 and Day7. The test was terminated 7 days after the plants were inoculated into the test vessels.

Controls and test vessels were kept in an incubator illuminated by continuous warm fluorescent lighting. Light intensity was $8000( \pm 100)$ lux as measured at the surface of the test solution. Temperature in the test vessel was $23 \pm 2{ }^{\circ} \mathrm{C}$. Growth medium was prepared and sterilised according to the OECD Guideline. Erlenmeyer flasks of $150 \mathrm{ml}$ volume were used as control and test vessels, with a randomised location. 


\section{Analysis of the data}

From the natural logarithm of number of fronds $(\operatorname{lnF})$ specific growth rate $(\mu)$ and percent inhibition of growth rate (Ir) were calculated as stated in the Guideline.

\section{Microcystin determination}

Microcystin content of the liophilised test material was determined by capillary electrophoresis (Vasas et al., 2006).

\section{Results}

Microcystin content of the liophilised test material was $2.836 \mathrm{mgg}-1$.The different test populations have shown striking differences in their response to Microcystis toxicity. In case of Lemnal $100 \%$ inhibition was recorded in the highest concentration, $2 \mathrm{mg} / \mathrm{ml}$, the next concentration, $1 \mathrm{mg} / \mathrm{ml}$ was still rather toxic, causing $45.24 \%$ inhibition (Fig. 1). Lemna2 proved more sensitive, with total (100\%) inhibition in the 2 $\mathrm{mg} / \mathrm{ml}$ and $1 \mathrm{mg} / \mathrm{ml}$ concentrations, but then a rapid decrease was experienced in the ecological response, the next concentration of $0.5 \mathrm{mg} / \mathrm{ml}$ caused only $8.81 \%$ inhibition (Fig. 2). In case of Lemna3, considerable toxicity (66.02 and $43.78 \%$ inhibition) was experienced in the concentrations of 0.125 and $0.25 \mathrm{mg} / \mathrm{ml}$, respectively (Fig. 3). Ecological response induced by the other (higher) concentrations did not exceed $20 \%$ (a sample is considered toxic if ecological response is above $20 \%$ /Suter, 1993/). Lemna4 did not show response, the highest inhibition was $6.65 \%$ in the $2 \mathrm{mg} / \mathrm{ml}$ concentration, but this is well below the toxic threshold (Fig. 4). Lemna5 showed toxic response (31.11 and $41.63 \%$ inhibition) in the two lowest concentrations (Fig. 5).

Not only sensitivity of the test populations differ but also, concentration-response relationships show different patterns. Lemnal and Lemna4 can be characterised by an almost ideal concentration-response relationship, meaning that the response steadily increases for each higher concentration (Fig. 1 and Fig. 4, respectively). Lemna2 (Fig. 2) shows an "all or nothing" response pattern, which is characterized by a transition from no significant effect at one effluent concentration to a complete effect $(100 \%$ mortality) at the next higher concentration. Even more interesting is the pattern shown by Lemna3 and Lemna5 (Fig. 3 and Fig. 5). These are typical inverse concentrationresponse relationships in which adverse effects decrease with increasing concentration. Most often, presence of nutrients may mask the toxic effect. 


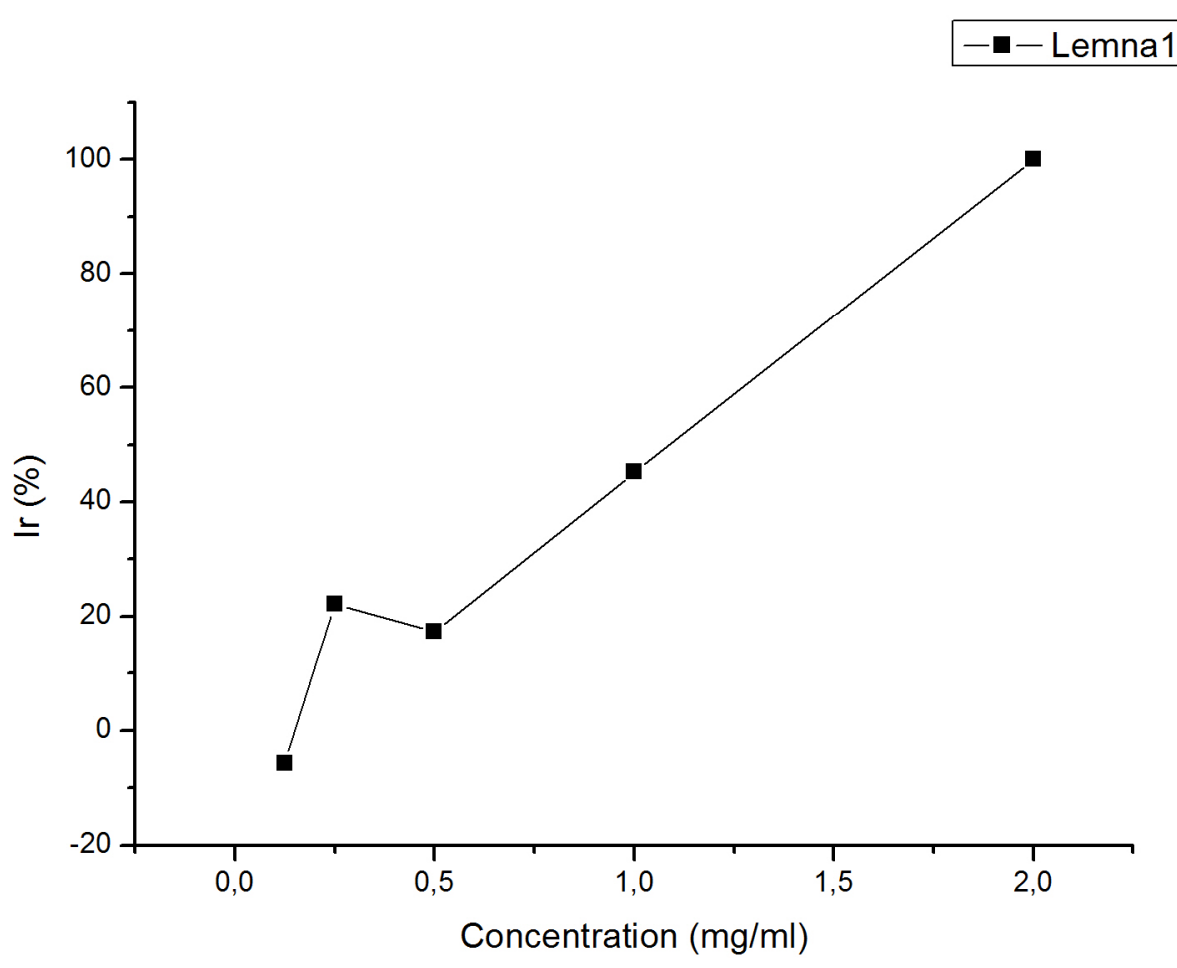

Figure 1. Concentration-response relationship for Lemnal

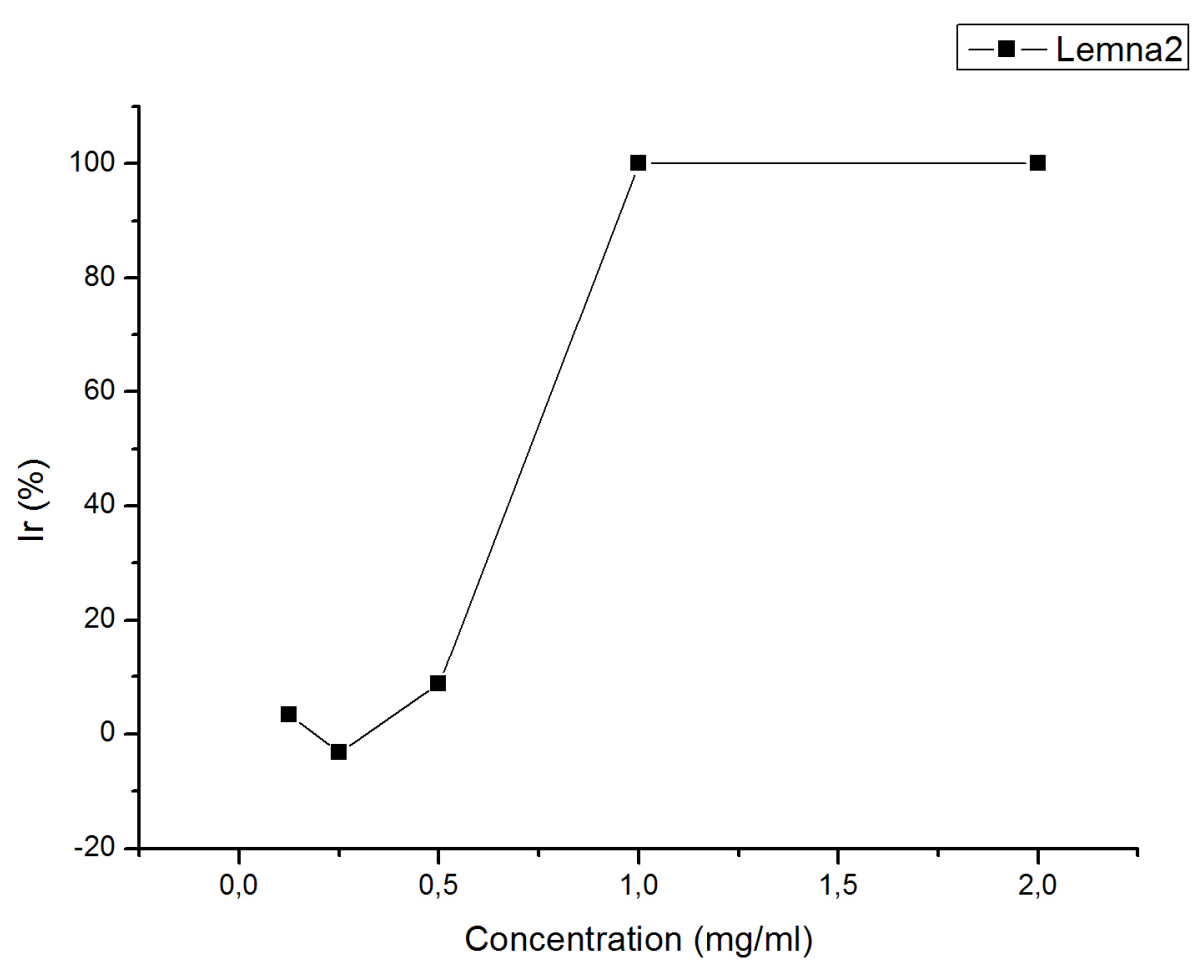

Figure 2. Concentration-response relationship for Lemna2

APPLIED ECOLOGY AND ENVIRONMENTAL RESEARCH 9(1): 17-26. http://www.ecology.uni-corvinus.hu • ISSN 15891623 (Print) • ISSN 17850037 (Online) (c) 2011, ALÖKI Kft., Budapest, Hungary 


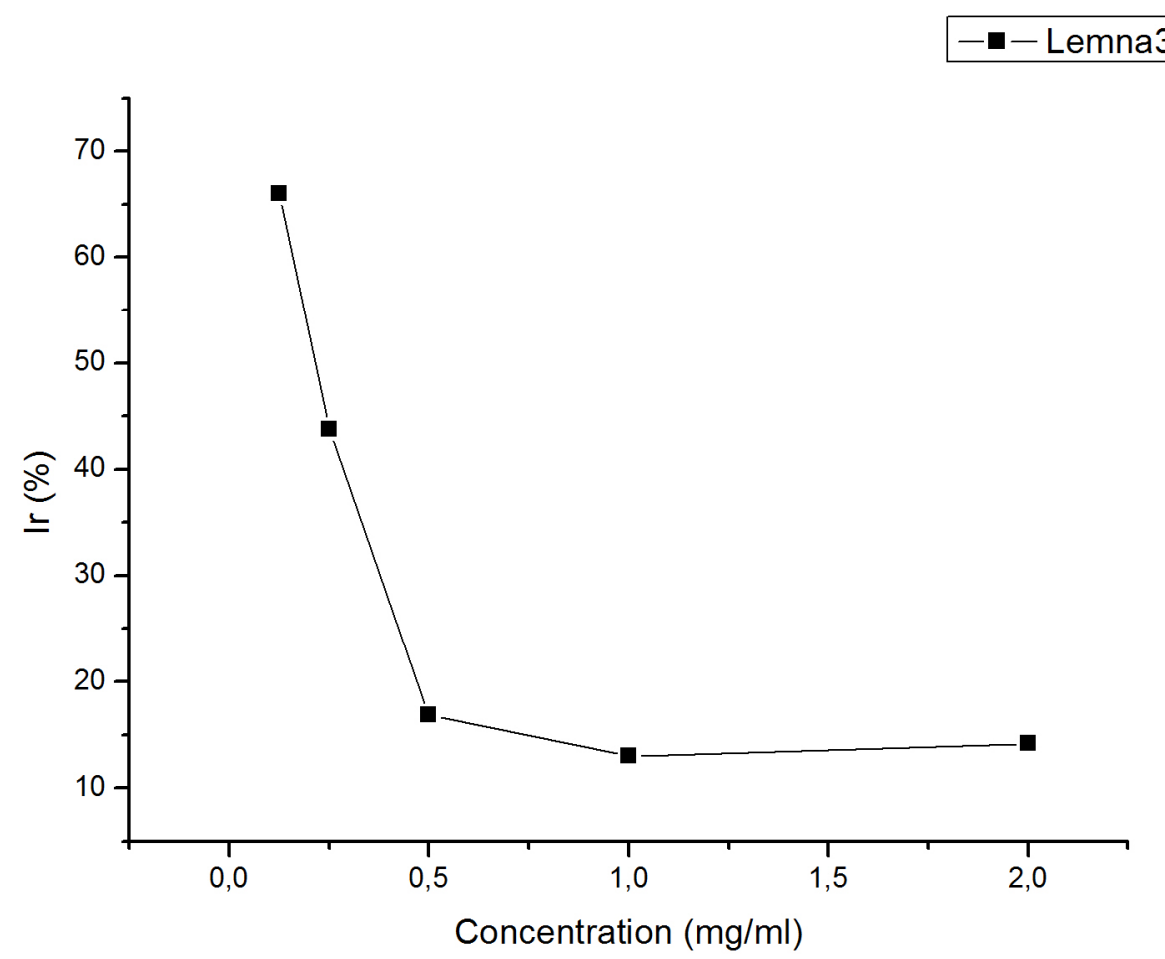

Figure 3. Concentration-response relationship for Lemna3

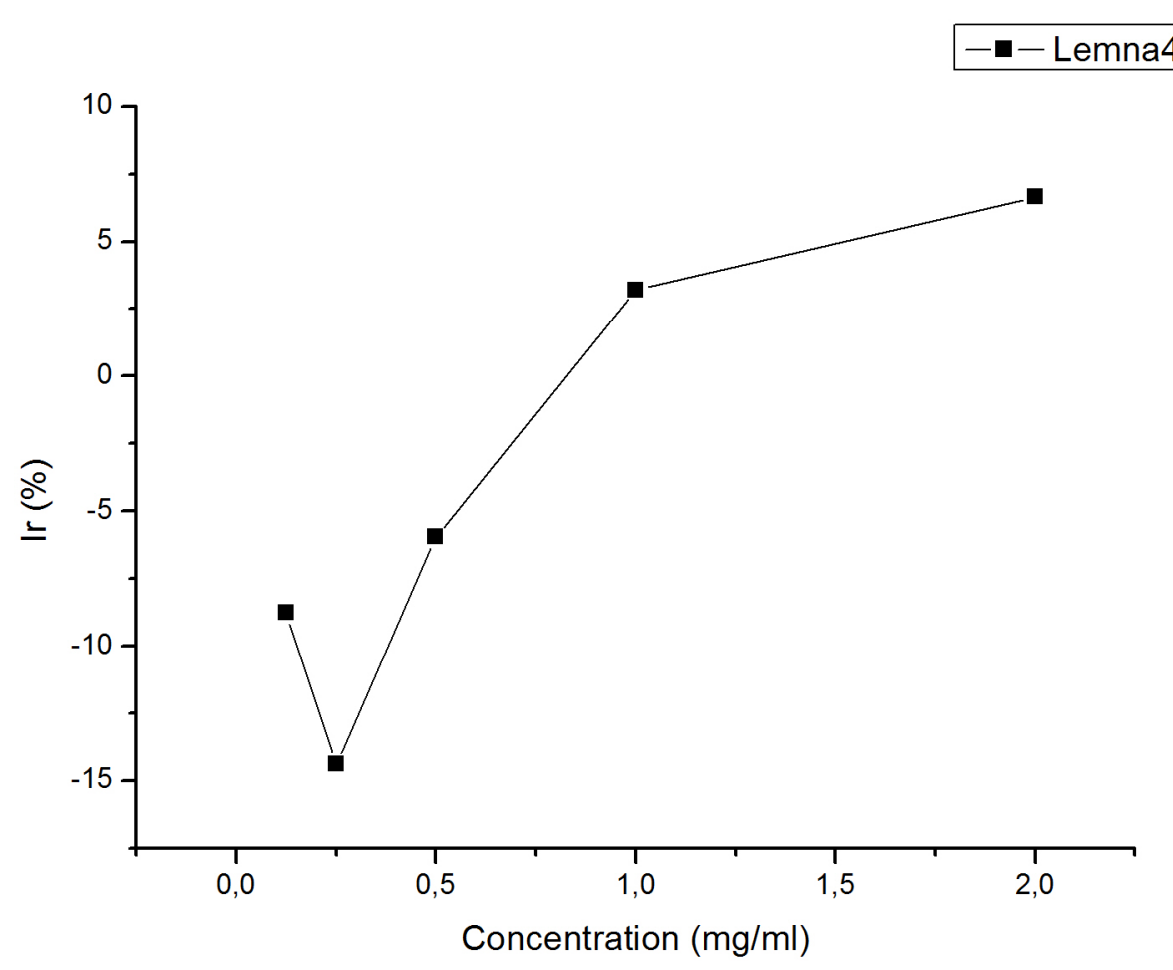

Figure 4. Concentration-response relationship for Lemna4 


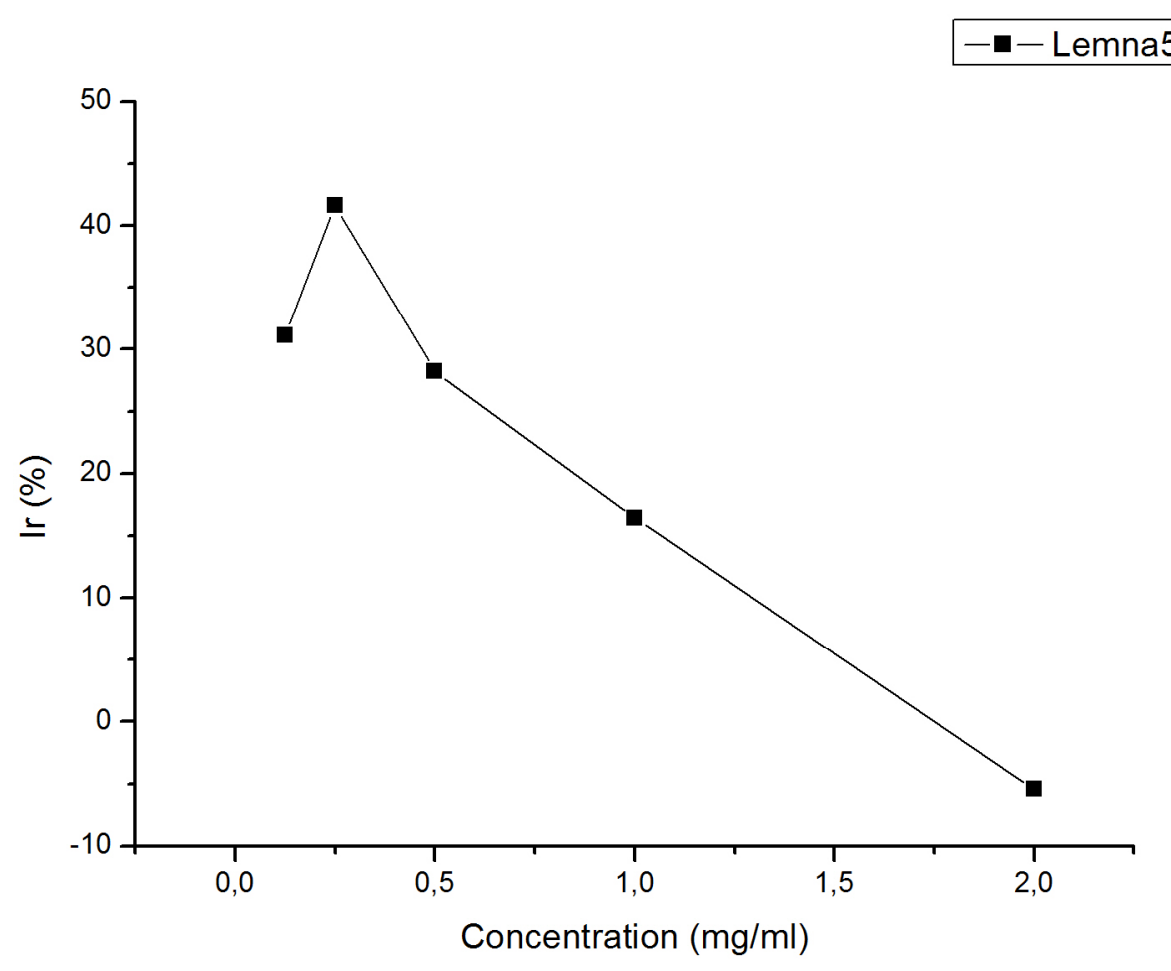

Figure 5. Concentration-response relationship for Lemna5

\section{Discussion}

Considering sensitivity, our null hypothesis was partially proven. We assumed that tolerance can be experienced in the case of Lemna clones which live in eutrophic habitats, and on the contrary, clones living in relatively pristine habitats would show sensitivity. Lemna2 (collected from an oligotrophic pond) showed the most significant response, as inhibition was $100 \%$ in the $2 \mathrm{mg} / \mathrm{ml}$ and $1 \mathrm{mg} / \mathrm{ml}$ concentrations. In the highest concentration, all fronds died by the end of the test and number of living fronds was lower than the original 20 in the $1 \mathrm{mg} / \mathrm{ml}$ concentration. It was followed by Lemna1 (collected from an oligotrophic, slow-flowing stream), expressing 100\% inhibition in the highest concentration, $2 \mathrm{mg} / \mathrm{ml}$, where number of living fronds were also reduced in comparison to the initial 20. It has to be noted that not only inhibition was experienced but visible syptoms: chlorosis and necrosis as well.

Lemna4 (collected from a slightly eutrophic pond) is also a rather clear case to analyse. Its concentration-response relationship is close to ideal (there is a slight anomaly in the second lowest concentration). It shows stimulating effects in concentrations $0.125,0.25$ and $0.5 \mathrm{mg} / \mathrm{ml}$, than a slight inhibitory effect in concentrations 1 and $2 \mathrm{mg} / \mathrm{ml}$. However, the highest inhibition amounts to only $6.65 \%$, therefore it can be concluded that Microcystis did not have any toxic effect on this test population., seemingly it showed practically complete resistance.

Our null hypothesis had assumed that Lemna3 would show the highest tolerance, as this clone was collected from the same habitat where toxic Microcystis bloom was 
experienced and where the sample Microcystis was collected. There is some indication that this clone had developed resistance, as higher concentrations of Microcystis during the test $(0.5,1$ and $2 \mathrm{mg} / \mathrm{ml})$ exerted rather low response, staying well below $20 \%$ of growth inhibition. However, the fact that lowest concentrations caused such high reproduction inhibition is difficult to interpret.

Lemna3 and Lemna5, however, as it was mentioned before, both show inverse concentration-response relationships but their sensitivity differ. For Lemna3, the 0.125 $\mathrm{mg} / \mathrm{ml}$ Microcystis sample had a very toxic effect, causing reproduction inhibition of $66.02 \%$. The second lowest concentration of $0.25 \mathrm{mg} / \mathrm{ml}$ still proved to be rather toxic, having an inhibitory effect of $43.78 \%$. The concentrations of $0.5,1$ and $2 \mathrm{mg} / \mathrm{ml}$ caused a somewhat uniform response of $16.87,12.96$ and $14.17 \%$ reproduction inhibition. The pattern is rather similar for Lemna 5, though extreme values are less extreme.

Biochemical explanation of resistance of higher plants is discussed in the Review of Literature. Duckweed is also capable of developing resistance, for example Saqrane et al. (2007) demonstrated that L. gibba could bio-transform microcystins and detected a suspected MC degradation metabolite. Mitrovic et al. (2004) measured the peroxidase activity (POD) of L. minor after exposure to several concentrations of the cyanotoxin, anatoxin-a. POD activity significantly increased after 4 days of exposure to an anatoxina concentration of $25 \mu \mathrm{g} / \mathrm{ml}$. Activity of a detoxication enzyme, glutathione Stransferase (GST) was also elevated at anatoxin-a concentrations of 5 and $20 \mu \mathrm{g} / \mathrm{l}$.

From ecological point of view these results clearly indicate that Lemna populations living in different habitat show very different response to Microcystis toxicity. We can come to the conclusion that it is rather impossible to estimate the response of an idealised Lemna minor to Microcystis toxicity - in fact, standard tests carried out on laboratory stock cultures might either underestimate or overestimate the actual risk. In case the actual risk of a field exposure by cyanobacterial toxins is to be assessed, we can advise to use Lemna clones which are collected from the vicinity of the bloom and which might well represent the actual recipients. Also, our results show that Lemna clones coexisting with cyanobacteria might acquire some "protection", by developing resistance.

\section{REFERENCES}

[1] Babica, P., Bláha, L., Marsálek, B. (2006): Exploring the natural role of microcystins - a review of effects on photoautrophic organisms. - J. Phycol. 42: 9-20.

[2] Environment Canada (1998): Biological test method: test for measuring the inhibition of growth using the freshwater macrophyte Lemna minor - Report EPS 1/RM/37.

[3] Ishida, K., Matsuda, H., Murakami, M., Yamaguchi, K. (1997): Micropeptins 478-A and -B, plasmin inhibitors from the cyanobacterium Microcystis aeruginosa. - J. Nat. Prod. 60: 184-187.

[4] ISO/FDIS (2007): Water quality - Determination of the toxic effect of water constituents and waste water on duckweed (Lemna minor) - Duckweed growth inhibition test.

[5] Jang, M-H., Ha, K., Takamura, N. (2007): Reciprocal allelopathic responses between toxic cyanobacteria (Microcystis aeruginosa) and duckweed (Lemna japonica). Toxicon 49: 727-733.

[6] Jungmann, D., (1995): Isolation, purification, and characterization of a new Daphniatoxic compound from axenic Microcystis flos-aquae strain PCC7806. - J. Chem. Ecol. 21: $1665-1676$. 
[7] Kamara, S., Pflugmacher, S. (2007): Acclimation of Ceratophyllum demersum to stress imposed by Phragmites australis and Quercus robur leaf extracts. - Ecotoxicol. Environ. Saf. 68(3): 335-42.

[8] Máthé, Cs., M-Hamvas, M., Vasas, G., Surányi, Gy., Bácsi, I., Beyer, D., Tóth, Sz., Tímár, M., Borbély, G. (2007): Microcystin-LR, a cyanobacterial toxin, induces growth inhibition and histological alterations in common reed (Phragmites australis) plants regenerated from embryogenic calli. - New Phytologist 4: 824-835.

[9] Mitrovic, S.M., Pflugmacher, S., James, K.J., Furey, A. (2004): Anatoxin-a elicits an increase in peroxidase and glutathione S-transferase activity in aquatic plants. - Aquat. Toxicol. 68: 185-192.

[10] Mitrovic, S.M, Allis, O., Furey, A., James, K.J. (2005): Bioaccumulation and harmful effects of microcystin-LR in the aquatic plants Lemna minor and Wolffia arrhiza and the filamentous alga Chladophora fracta. Ecotoxicol. - Environ. Saf. 61(3): 345-52.

[11] Mohamed, Z.A. (2008): Polysaccharides as a protective response against microcystin induced oxidative stress in Chlorella vulgaris and Scenedesmus quadricauda and their possible significance in the aquatic ecosystem. - Ecotoxicology 17: 504-516.

[12] Mohamed, Z.A., Al Shehri, M (2010): Microcystin production in epiphytic cyanobacteria on submerged macrophytes. - Toxicon 55: 1346-1352.

[13] OECD (2002): OECD Guidelines for the Testing of Chemicals: Lemna sp. Growth Inhibition Test. - Draft Guideline 221.

[14] Pflugmacher, S. (2002): Possible allelopathic effects of cyanotoxins, with reference to microcystin-LR, in aquatic ecosystems. - Environmental Toxicology 4: 407-413.

[15] Pflugmacher, S. (2004): Promotion of oxidative stress in the aquatic macrophyte Ceratophyllum demersum during biotransformation of the cyanobacterial toxin microcystin-LR. - Aquat. Toxicol. 10; 70(3): 169-78.

[16] Pflugmacher, S., Wiegand, C., Beattie, K.A., Krause, E., Steinberg, C.E., Codd, G.A. (2001a): Uptake, effects, and metabolism of cyanobacterial toxins in the emergent reed plant Phragmites australis (cav.) trin. ex steud. - Environ. Toxicol. Chem. 20(4): 846-52.

[17] Pflugmacher, S., Ame, V., Wiegand, C., Steinberg, C.E.W. (2001b): Cyanobacterial toxins and endotoxins their origin and their ecophysiological effects in aquatic organisms. - Wasser Boden 53/4: 15-20.

[18] Romanowska-Duda, Z, Tarczynska, M. (2002): The influence of microcystin-LR and hepatotoxic cyanobacterial extract on the water plant Spirodela oligorrhiza. - Environ. Toxicol. 17(5): 434-40.

[19] Sedmak, B., Kosi, G. (1998): The role of microcystins in heavy cyanobacterial bloom formation. - J. Plankton Res. 20: 691-708.

[20] Sivonen, K., Jones, G. (1999): Cyanobacterial toxins. - In: Chorus, I. and Bartram, J. (Eds.) Toxic Cyanobacteria in Water: A Guide to their Public Health Consequences, Monitoring and Management, London: E. \& F.N. Spon. 41-111.

[21] Suter, G.W. (1993): Ecological risk assessment. - Lewis Publishers, Boca Raton.

[22] Stüven, J., Pflugmacher, S. (2007): Antioxidative stress response of Lepidium sativum due to exposure to cyanobacterial secondary metabolites. - Toxicon. 50(1): 85-93.

[23] Szigeti, Zs.M., Jámbrik, K., Roszik, J., Hamvas, M., Tándor, I., Beyer, D. Vasas, G., Vereb, Gy., Surányi Gy.,Máté, Cs. (2010): Cytoskeletal and developmental alterations in Ceratophyllum demersum induced by microcystin-LR, a cyanobacterial toxin. - Aquatic Botany 92: 179-184.

[24] Vasas, G., Szydlowska, D., Gáspár, A., Welker, M., Trojanowicz, M., Borbély, G. (2006): Determination of Microcystins in Environmental Samples Using Capillary Electrophoresis. - J. Bioch. Bioph. Meth. 6: 87-97.

[25] von Elert, E., Oberer, L., Merkel, P., Huhn, T., Blom, J.F. (2005): Cyanopeptolin 954, a Chlorine-Containing Chymotrypsin Inhibitor of Microcystis aeruginosa NIVA Cya 43. J. Nat. Prod. 68: 1324-1327. 
[26] Weiss, J., Liebert, H.P., Braune, W. (2000): Influence of microcystin-RR on growth and photosysnthetic capacity of the duckweed Lemna minor L. - J.Appl.Bot. 74: 100-105.

[27] Wiegand, C., Peuthert, A., Pflugmacher, S., Carmeli, S. (2002): Effects of microcin SF608 and microcystin-LR, two cyanotobacterial compounds produced by Microcystis sp., on aquatic organisms. - Environ. Toxicol. 17(4): 400-6.

[28] Yi, D., Yijun, Z., Xue, B., Zhihui, F., Kai, C. (2009): Phytotoxic effects of cyanobacteria extract on Lemna minor and Myriophyllum spicatum phyto-tolerance and superoxide dismutase activity. - Environ. Toxicol. 24: 304-308.

[29] Yin, L., Huang, J., Li, D., Liu, Y. (2005): Microcystin-RR uptake and its effects on the growth of submerged macrophyte Vallisneria natans (lour.) hara. - Environ. Toxicol. 20(3): 308-13. 